\title{
Perspectives from Dr. Charles Drake: Early Training in Toronto
}

\author{
by Charles G. Drake
}

Can. J. Neurol. Sci. 1999; 26: 331-333

During the final months of his courageous battle with lung cancer, Dr. Charles Drake was preparing an address which he had been asked to deliver at the 75th anniversary of Dr. Kenneth G. McKenzie's appointment as the first neurosurgeon at the University of Toronto (75 Years of Neurosurgery in Canada, October 31st, 1998). Anticipating that he would be unable to stand to deliver the address, he asked that arrangements be made to allow him to deliver it from a wheelchair beside the podium in Toronto. He died suddenly from a pulmonary embolus on September 15th. The address was given posthumously by his son, pediatric neurosurgeon Dr. James Drake.

My nine-month, war-shortened, junior rotating internship early in 1944 was at the Toronto General Hospital where I was the only outsider and from Western. Not having seen much surgery, I was fascinated with what surgeons could do for disease.

My last rotation was on neurosurgery with Dr. Kenneth McKenzie and I could hardly believe what I saw him doing with the brain and spinal cord. No sooner had I arrived on the service when Dave Bohnen, his only senior resident at the time, and who subsequently became surgeon-in-chief at Mt. Sinai, lost most of the skin off his hands from what we then called an $i d$ reaction to rubber gloves. I was then alone on this huge service and I worked like a dog. Whether or not it had anything to do with our relationship, I don't know, but within a few evenings on the service I was confronted with a man deeply stuporous in the Emergency Room with a boggy temporal swelling, a fixed dilated pupil and opposing hemiparesis. His wife told me that he had regained consciousness for a brief period after falling down stairs before vomiting and subsequent neurological decline. Perhaps the only thing I learned about head injuries as a medical student was that this must be an acute extradural hematoma and a real surgical emergency. I called Dr. McKenzie at home only to be told by Mrs. McKenzie that he was at a formal dinner at the Royal York. I am sure I rethought the situation for an instant but then phoned the hotel and finally had him on the line - "are you sure?" I said yes. "Get the OR set up." He arrived in the OR in his evening dress to look at the patient on the stretcher. You may only imagine my relief when in the incision through that boggy swelling thick fresh clot squirted out of the burr hole just made. Miss Duthie showed me his operative note the next day wherein he had paid me a small compliment. It made my day and strengthened my regard for the man.

On my last day coming down on the elevator after rounds in the private patients' pavilion, he asked me if I had enjoyed the service. "Yes Sir." Had I had any interest in pursuing a neurosurgical career? "Yes Sir." "Well then come back and see me after the war."

Dr. McKenzie knew and admired Dr. Penfield for his continuing devotion to scientific studies. He was well aware of his own shortcomings and wanted his residents to have more training in neuroscience. As a result, I ended up studying neuroanatomy and neurophysiology for three years beginning at
Western under no less than Barr, Miller and Stavraky and then at Yale in John Fulton's department. In New Haven, Frank Nulsen and I studied functional localization in the anterior cerebellum in primates up to the chimpanzee. We were actually able to produce a cerebellar primunculus, a primate version of Dr. Penfield's homonculus of the cerebral cortex. I had to admit that the cerebellar one would not have the same functional significance.

When I came back to Toronto in 1949, Harry Botterell was back from overseas with thoughts about enlarging the training program. I would have to say that KG [Dr. McKenzie] had some misgivings. He did not believe in the wholesale enlargement of the training programs in the United States, largely to satisfy the popular demand for a neurosurgeon to look after every head and spine injury. He told me that only a few should be trained to look after the heavy gamut of nontraumatic disorders. Head injuries could as well be looked after by general surgeons who had some training with burr holes and craniotomy for clots, supported by the special nursing care of the day. Sometimes I am not sure what more neurosurgery can do today for the immediate awful consequences of milliseconds of acceleration or arrest after impact, with the stretching or even tearing of axons of the brain interior. Anyway, I did not deign to train any but general surgeons for at least 10 years after opening the service at Western - and I may say that they did a pretty good job of recognizing and removing clots before referral from the more remote areas of southwestern Ontario; remember we had only hypertonic saline and surface transportation. I no longer had the gut wrenching telephone call from a physician in Owen Sound that a boy was on his way down for a three hour ride in an ambulance in coma with a fixed dilated pupil after being boarded at a hockey game and then vomiting afterward in the dressing room.

By tacit consent, after my first few months as a senior, I worked more with Dr. McKenzie, perhaps because I was his last selection - at least that is what he told me. As a surgeon he was superb, a master nearly unequaled in his time. I was privileged to watch the best of that day later in the United States and in the

Reprint requests to: Stephen P. Lownie, Neurosurgery and Endovascular Therapy, London Health Sciences Centre, University Campus, 339 Windermere Road, London, Ontario, Canada N6A 5A5 
United Kingdom and Europe - few were his equal. His touch on the brain whether with his forefinger searching for a soft spot overlying a deep glioma or with the forceps or retractor was gentle and there followed beautiful technical precision. There was one exception. In those days the arterial venous bundles entering a glioma on the cortical surface were encircled with silk sutures which were then tied tightly and divided. The pial tears so created were then joined around the surface aspect of the tumour. Using Dandy's technique he would encircle the tumour's hidden depth with his forefinger occasionally clipping a vessel entering the deep portion and then tilting the mass out of its bed, all in a few minutes. The patients did well with a tight closure so that they did not linger for a long time after straightening out their affairs and going fishing. He was a master with meningiomas, teasing the pia-arachnoid back before using the cutting loop for morcellation, even separating "wraparound" tumour from the carotid or middle cerebral arteries in Sylvian tumours.

His surgical hobbies then were section of only the vestibular portion of the eighth nerve for Meniere's disease, spasmodic torticollis, various pain tract sections, sympathectomy for hypertension and lobotomy. His interests were largely technical including some well known instrumentation. He would brood over how best to tackle a difficult problem particularly if it had an anatomical base. He called the acoustic neuroma the queen of brain tumours. They were all huge in those days and Eben Alexander showed that he had one of the lowest morbidities of the time. He said that the glioblastoma was made for the resident surgeon. The two things he loved to do because the patients had such good outcomes were a chronic subdural hematoma and a benign spinal cord tumour before the patient had become paraplegic.

Dr. McKenzie was imperturbable even in very difficult surgical situations, carrying on to pursue a solution. When I erred, I can't recall him scolding me. He would merely look at me over his glasses for a moment or two but without comment and then continued.

As many of you will know, the surgical treatment of an intracranial aneurysm was a rare event even after Dott and Dandy's landmarks of the 1930s. Often it was the fortuitous exposure of what was felt to be a large tumour. I had four experiences with $\mathrm{KG}$ and an aneurysm.

I recall exposing a large left Sylvian mass for him which he took to be a meningioma. On opening to gut it, old thrombus extruded. Even knowing that it was an aneurysm he proceeded to empty it with pituitary rongeurs and when bleeding appeared he emptied it even more to get room to get a clip on the middle cerebral artery. The woman did not survive. Incidentally that was not his first experience. At the Cushing meeting in 1938, in discussion of German's paper, he mentioned excising a large aneurysm.

EHB [Harry Botterell] had some interest in using carotid occlusion for aneurysm and Dott's proximal occlusion of A1 for anterior communicating aneurysms and he was anxious to try clipping the neck for the first time. A man in his 50s was admitted under him with a right middle cerebral aneurysm in good condition. Harry had to be out of town for the weekend but said he wanted to clip it on Monday as the first case. On Saturday the patient rebled with a severe hemiparesis. I called
$\mathrm{KG}$ and he said to take the clot out and call him if there were any difficulties. You know how inquisitive residents are, so after removing the clot and with a slack brain I began to look around the bifurcation teasing the clot away little by little and there was the aneurysm no more than a $\mathrm{cm}$ in size but arising from an M2 branch nearby. It looked angry so I called KG again and he said "Charlie you had better clip it or excise it". The McKenzie clip seemed too short so I excised it. The patient had a reasonable outcome but with a hemiparesis. And that was the aneurysm that was mounted and exhibited in Dr. Boyd's wonderful museum until its untimely destruction. Harry wasn't all that pleased that $\mathrm{I}$, as a resident, had dealt first directly with a ruptured aneurysm in Toronto. Anyway it made my day and had a big impact on my thinking for the future.

After that KG became interested in the aneurysm story, so I roamed the medical wards where most cases arrived under Herbie Hyland or Rick Richardson, who were then treating them with daily lumbar punctures! Over those months I remember three woman dying from rebleeding while I was trying to get permission to transfer them. One died on the bedpan while I was waiting outside the curtain on Ward G.

$\mathrm{KG}$ did operate on two more in my time, both small carotid communicators. Why he didn't use a clip on the first one, I can't recall. Instead he put a pin suture through the neck, then in the bleeding he encircled the neck and tied it down, although the bleeding did not abate completely until packed in crushed muscle. In the other, he coagulated the sac with the Bovie as he had heard that Dandy did occasionally. I recall dimly that the patient survived with a charred aneurysm. Anyway, when I left Toronto, he told me he thought there was a future in the treatment of aneurysms, that he was too old to take it on seriously and that I should have a "crack" at it.

His subtemporal tic operation was a joy to watch. But I remember him telling me that after exposing the dura propria of the ganglion in one case, he had run into such cavernous sinus bleeding that he had to quit - but the patient became pain free. Well it happened to me too and it made me think about it. And so I did a dozen cases from the public ward without opening the dura propria after it had been exposed. You could do that then, and all were pain free except one, who became so after another few wipes with a pattie over the dura propria. I wrote a small paper on it, but he did not want to see it published so soon, I was to wait five years for his support. Meanwhile, Hunter Sheldon was enlarging the foramen ovale with a drill so my little adventure did not see print. It was about that time that KG told me to try to publish at most two papers a year after peer review; no man could or should do more alone.

In the fall of 1950, when I was completing my first year as clinical assistant, he spoke to me in his dressing room in "D" O.R. after I had been on the service for only $1 \frac{1}{2}$ years - "Charlie you don't need any more training here. I have made arrangements for a small fellowship for you to go overseas and visit some of the great surgeons in the U.K. and Europe. Harry Botterell thinks you should do a clerkship in Neurology at Queen Square." However, as Dr. Cushing had told Dr. McKenzie, he wanted me to go overseas alone without Ruth and the baby John, so that I could devote all my time to learning. Ruth was upset and, of course, came along although the honorarium barely covered the sea passage alone. We shared a 
house south of London with Kay and Henry Barnett which made it easier for Ruth.

Most rewarding were my months at Oxford with Sir Hugh Cairns then in Stockholm with Olivecrona and in Paris with Gérard Guiot, that unsung French neurosurgeon. In Stockholm Dr. McKenzie wanted me to see how Olivecrona saved the facial nerve which he had never been able to do. Olivecrona never resected the outer third of the cerebellum, but underneath gutted the tumour very thoroughly, then teased the capsule away with piecemeal removal and then rotated the residual shell so as to reveal the flattened band of the nerve and gently tease it away back to the pons. But at the porus it was very simple; he simply divided the tumour from the nubbin within the porus which he proceeded to coagulate thoroughly with a long blunt hook. No doubt he cooked the nerve too, but said it would regenerate. But it was in Stockholm that I learned their aneurysm techniques, finally using linen threads to occlude the neck, which I used off and on for years. Olivecrona was the first to remove an AVM from the cerebellum in 1932. I watched him take a large one from Broca's area beautifully, although he tied off the deep portion with a suture so as to remove most of the mass. But that Metropolitan diva never sang again and probably had later recurrent bleeding from the stump.

In 1951, Guiot in Paris was dividing the ansa lenticularis with a blunt hook through the anterior perforated substance with remarkable relief of tremor. He had also brought back the transsphenoidal approach to the sella from Norman Dott in Edinburgh with whom he had trained. For reasons that escape me, I followed up on neither of these.

So that was my training after only $1 \frac{1}{2}$ years of neurosurgical residency. This was astounding to the American Board of Neurological Surgery, many years later, when they asked me to join them, until they read my CV. I did not keep the letter of condolence which also told me that unfortunately I would not be eligible for their examination unless I took more resident time and then I might be able to join them later.

Dr. McKenzie wanted me to continue with him in Toronto and I signed the contract which he had sent over to England. When I came back in the fall of 1951 for some neuropathology, the exams and looking after EHB's interests in Sunnybrook, the situation had changed. There had been a persistent pressure that I return to Western to start a service there under Dr. Angus McLachlin. Finally, KG after brooding about it, felt it might be best, for he knew of the good physiology labs there and the large amount of clinical material. He intimated that he was worried that under such a dominant figure as EHB, I may not "blossom" as well as if I were on my own. Not without some misgivings, for I really wanted to continue to work with him, Ruth and I returned to London. It took some time, but it turned out reasonably well, especially after Henry Barnett decided to join us in 1969.

It many ways $\mathrm{KG}$ acted like a father towards me perhaps because he knew mine had died before I was born. He introduced me to fly fishing and we discussed upland and water fowl hunting and golf. He felt that such outdoor interests were the key to a successful surgical life.

As a consequence, after returning to London, I took him to Pelee Island for the two day pheasant shoot every fall with some surgical friends, for most of his remaining years. I flew him down from Toronto in my old Cessna 195. I know he had a marvellous time. His was a ritual, after plucking his birds to the very last feather - after drinks. A good supper, some bridge and we often slept on the open porch under the stars. Sometimes we stopped in London on the way back for a game of golf. He was very interested in the neuromuscular basis of the game. And he insisted on coming down to London to watch me do my first acoustic neuroma.

\title{
Comments on Early Publications of Charles Drake
}

\author{
Gary G. Ferguson
}

Dr. Zochodne, the Editor of the Canadian Journal of Neurological Sciences expressed a desire to re-publish an article written by Dr. Drake to accompany the "In Memoriam" and asked me to recommend what I considered to be "the best". No easy task, as many of his original articles were of considerable importance. Charles Drake made his reputation as a masterful neurosurgeon very early in his career and I believe that his earlier publications are of particular interest. One is reproduced in this issue (page 335). In my opinion, it demonstrates his exceptional boldness and surgical prowess, the lucidity of his thought and his willingness to co-operate with colleagues and profit from their particular skills and experience.

His publication relating to posterior circulation aneurysms, "Bleeding Aneurysms of the Basilar Artery. Direct Surgical Management of Four Cases" was published in 1961 in the Journal of Neurosurgery. This publication lead to immediate international recognition for Dr. Drake. I remember as a third year medical student at Western, sitting in the Busby Lecture Hall at the old Victoria Hospital in the fall of 1963, to hear a guest lecture by Dr. E.H. Botterell, who had been introduced by Dr. Drake. Dr. Botterell began by saying, "Do you students realize that Dr. Drake is world-famous for his ability to treat basilar aneurysms?" Who could have imagined at the time of his first paper, that it was the beginning of an unparalleled experience in posterior circulation aneurysms, that would culminate 35 years later in the publication of a book describing the experience of 1767 such patients treated in London, Ontario. I believe the initial publication is interesting for a number of reasons: what would become the standard approach for basilar bifurcation and upper basilar trunk aneurysms had already been determined (anterior subtemporal), innovative surgical adjuncts were incorporated into procedures (hypothermia, lumbar drainage, local cerebral circulatory arrest) and the potential consequences of vasospasm were recognized. 